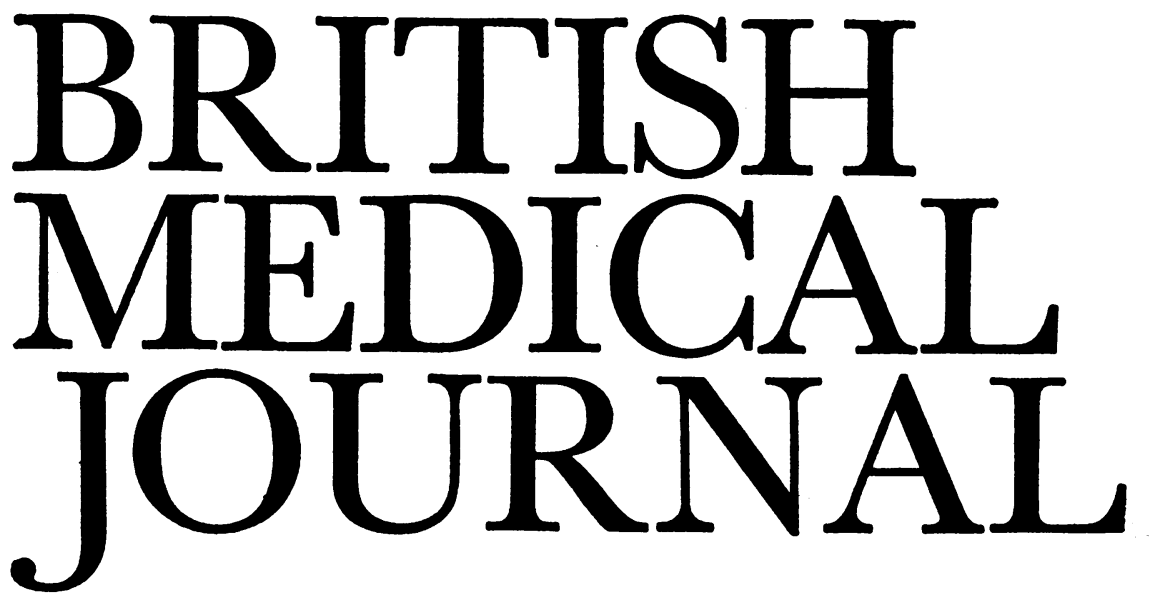

LONDON SATURDAY 20 APRIL 1974

\title{
Talking about Death
}

The problem of what a seriously ill patient should be told about his illness is one which constantly exercises the minds of those with clinical responsibility. Discussion of this perennial question has recently erupted once again in the B.M.F., where it has been focussed on what to tell a patient who is found to have cancer. Most of those who expressed their views were surgeons-an uncompromising branch of our profession who tend to see matters starkly as either black or white. To many doctors, however, this is a grey area where rule-of-thumb methods and rigid rules cannot be applied. It is a topic never taught and seldom mentioned in medical schools, and the doctor entering practice can reasonably be excused his uncertainty and confusion.

It has been suggested that whether we have the right to withold diagnostic information from patients is the fundamental ethical question, but patients ask to be made well; they do not ask for "diagnostic information." The very phrase suggests an ex cathedra pronouncement which is outmoded. The doctor is no longer a member of an authoritarian priesthood. Medical care should be a co-operative venture involving the doctor, the patient, and the patient's family. Ideally, all should be en rapport; nothing should be hidden; there should be no prevarications; all the patient's problems and how they can be met should be freely discussed.

In an imperfect world this ideal situation is unhappily rare, and the variables are many. These include not only the nature of the disease but the character of the patient and the personality of the doctor. It is clear that whatever the information to be imparted the patient must have sufficient intelligence to understand what he is being told. To take an extreme example, nothing would be gained by explaining details of his illness to a high-grade mental defective. It is easy to forget that medical and pathological concepts which are the small change of the doctor's daily thinking are often meaningless to intelligent laymen. The explanation must be in words the patient can understand, and the doctor must resist the temptation to hide behind a terminological barrage. The exposition should, moreover, be sufficiently matter of fact to maintain a low emotional temperature.

It has often been said that in grave disease of the type we are discussing few patients are able to withstand the impact of being told the bald truth. This must depend upon what the truth is, the way in which it is revealed, and the character of the patient. Few can bear to be deprived of all hope at a single stroke, but when effective treatment is available the blow is softened, and this is true in lesser degree when any treatment, even if unlikely to be effective, is offered. The most stoical and courageous can hardly regard with equanimity the prospect $_{2}$ such as that of motor neuron disease, of a slowly progressive, relentlessly fatal disorder.

The character of the patient has a major influence on the doctor's decision, but it would be a brave and probably inexperienced man who claimed to assess this factor with confidence. Many will have seen the patient apparently of iron will who, when told he has cancer, turns his face to the wall. Many will have been made to feel humble by the patient, previously regarded as shallow and vain, who receives such news with philosophical fortitude. Many more will have seen the patient's face light up with relief when he is told frankly but kindly the facts about his illness. However bleak these may be the knowledge of them dispels the corroding uncertainty and suspicion and gives him the courage to face a situation he understands. Moreover, the spirit of frankness adds a new dimension to the relationship of doctor and patient and to the effectiveness of their co-operation.

It is impossible to be certain how patients will react to such information. It is often wise not to volunteer unpalatable facts uninvited. There is an occasional patient who prefers not to discuss such matters with his doctor, though virtually certain of the truth and aware that the doctor knows what is in his mind. It is as though he fears that when the veil is torn away and his pathetic deception revealed, morale will crumble, and the dignity with which he faces the world will disappear. This -reserve must not be assaulted abruptly, but if he can be brought to discuss his problems frankly he will lose much of his tension and anxiety.

Another patient will phrase his questions to show that he is seeking reassurance rather than the truth. It is tempting to give him the opinion he demands, but this temptation should be resisted. It is usually disastrous to lie. The doctor rapidly becomes entangled in a web of myth and deceit; there always comes a time when the truth is only too apparent, and with this realization the patient feels that he has been betrayed and can no longer place his trust in his doctor.

The personality of the doctor is clearly almost as important as that of the patient in this exchange. Awareness of the problems and experience are invaluable, but much depends upon the innate qualities we believe to be those of a good doctor: 
patience, understanding, tact, and imaginative sensitivity. These will provide him with the capacity to communicate with his patient without the embarrassment discussion of death so often arouses.

There is no easy answer to this most difficult of questions. Each doctor will continue to answer it in the way he thinks fit, and if his solution is inspired by kindness, honesty, and simplicity it will probably bring help and comfort to his patient.

1 British Medical Fournal, 1973, 1, 29.

2 Milton, G. W., British Medical fournal, 1973, 4, 221.

8 Wright, C., British Medical fournal, 1973, 4, 45.

- Green, R., British Medical fournal, 1973, 4, 231.

5 Lindahl, J. W. S., British Medical fournal, 1973, 4, 296.

- Walter, J., British Medical fournal, 1973, 4, 425.

\section{Alcoholism and its Identification}

The Standing Medical Advisory Committee of the Central Health Services Council has produced an excellent memorandum on alcoholism. ${ }^{1}$ In the space of 13 pages it gives an overall view of the problem and focuses on practicalities. The particular concern of this report is early diagnosis and the role of the general practitioner. Full of common sense, it is written in lively English with even a hint of raciness.

The essential message is that alcoholism is an illness which is treatable, and the sooner the diagnosis is made and treatment started the better. The hospital specialist sees clear-cut and advanced cases. The challenge to the family doctor is that he should develop the sensitive skill needed to pick up the diagnosis of a condition which the patient himself may be eager to hide because of embarrassment and guilt. The report's common-sense advice is that the doctor should not fear to mention excessive drinking and he should keep an eye open for the story behind the story whenever a patient asks for a certificate on Monday morning, complains of gastritis or vaguely of "bad nerves", or seems for no apparent reason to be becoming a bit seedy. The only fault to find with this otherwise admirable document is that a one-line reference to Alcoholics Anonymous is not enough. Every general practitioner ought to have its literature to hand for giving to his patients, and he should also have the telephone number of a local A.A. sponsor and know how to effect an introduction.

An interesting view of Great Britain's services for the treatment of alcoholism is to be found in a publication issued by the European Office of the World Health Organization. ${ }^{2}$ It constitutes something of an independent assessment. The report rightly focuses on some limitations in our present approach. We do not have enough concern for prevention, and the recent official reports on liquor licensing in England and Wales ${ }^{3}$ and in Scotland ${ }^{4}$ provide clear evidence of our lack of any integrated policy to meet this large medico-social problem. Licensing in those reports was seen more as a matter of public order, the convenience of the drinker, and the expectations of the tourist than as an influence on public health. ${ }^{56}$ The W.H.O. Report also finds fault with us for having done too little for skid-row alcoholics presenting as chronic-drunkenness offenders. This type of publication exemplifies the useful role which W.H.O. can play as friendly critic and stimulus to self-examination.

Alcoholism has for long been one of Britain's most neglected health problems. Greater and more purposeful investment in research is needed. ${ }^{7}$ Treatment services are improving, but there is still a large gap between the Health Departments' intention and the actuality which faces the general practitioner in many places. Moreover education within the profession is needed, and the newly founded Alcoholism Education Centre in Denmark Hill, London, supported by the Department of Health, is addressing itself to a very real need.

1 Department of Health and Social Security, Alcoholism. Prepared by the Standing Medical Advisory Committee for the Central Health Services Council. November 1973.

2 World Health Organization, Existing Patterns of Services for Alcoholism and Drug Dependence. Regional Office for Europe, Copenhagen, 1973.

${ }^{3}$ Report of the Departmental Committee on Liquor Licensing. London, H.M.S.O., 1972 .

- Report of the Departmental Committee on Scottish Licensing Law. Edinburgh, H.M.S.O., 1973 .

5 British Medical fournal, 1972, 4, 625.

- British Medical Fournal, 1973, 4, 64.

7 British Medical fournal, 1973, 3, 602.

\section{Intrathoracic Foregut Cysts}

Intrathoracic cysts derived from developmental defects of the foregut account ${ }^{1}$ for about $10 \%$ of primary mediastinal tumours, and Kirwan, Walbaum, and McCormack ${ }^{2}$ have recently described 41 such cysts seen in the Edinburgh Thoracic Unit between 1948 and 1971. These cysts have yet to find a generally acceptable name, which should if possible denote their embryonic nature and their site of origin. Perhaps the familiar "foregut cyst" followed by the anatomical site when this is known is the most appropriate.

The notochord appears in the third week of embryonic life. Occasionally it splits, leaving a gap in the dorsal tissue mass. The endodermal gut rudiment may herniate through the gap and form a cyst, sinus, or fistula, sometimes with vertebral defects. When a cyst develops, it lies in the posterior mediastinum attached to the spine and usually separate from the oesophagus. As the foregut elongates more rapidly than the spine, the cyst may be situated caudal to the vertebra to which it is attached, and this variety is sometimes called the split notochord syndrome. ${ }^{3}$ The respiratory system, deriving from a median ventral diverticulum of the foregut, may bud abnormally with the formation of tracheal and bronchial cysts. The oescphagus, almost a solid tube in early development, forms vacuoles which coalesce to establish the lumen. A persistent vacuole may proceed to an intramural oesophageal cyst, sometimes referred to as a duplication.

Foregut cysts vary considerably in size and may be $10 \mathrm{~cm}$ in diameter or more. Half give no symptoms at the time of discovery by routine radiography. Some cause thoracic pain of sufficient intensity for medical advice to be sought. A minority cause formidable complications due to pressure or infection. A small tracheobronchial cyst can cause extreme dyspnoea, especially in infants, which may be fatal if untreated. Larger cysts exert varying degrees of pressure on the trachea or oesophagus, leading to breathlessness or dysphagia or both, while bronchial cysts are often associated with recurrent pulmonary infections. Infected mediastinal cysts may rupture into any of the surrounding structures, including the mediastinum and pericardium, with grave consequences. Thrombophlebitis of the great vessels sometimes occurs.

The differential diagnosis is difficult, the usual presentation being a mediastinal opacity in a radiograph with few or no symptoms attributable to it. Carcinoma of the bronchus or 